IZA DP No. 7283

Fighting Poverty: Assessing the Effect of Guaranteed Minimum Income Proposals in Québec

Nicholas-James Clavet Jean-Yves Duclos

Guy Lacroix

March 2013 


\title{
Fighting Poverty: Assessing the Effect of Guaranteed Minimum Income Proposals in Québec
}

\author{
Nicholas-James Clavet \\ CIRPÉE, Université Laval \\ Jean-Yves Duclos \\ CIRPÉE, CIRANO, Université Laval \\ and IZA \\ Guy Lacroix \\ CIRPÉE, CIRANO, Université Laval \\ and IZA
}

Discussion Paper No. 7283

March 2013

\author{
IZA \\ P.O. Box 7240 \\ 53072 Bonn \\ Germany \\ Phone: +49-228-3894-0 \\ Fax: +49-228-3894-180 \\ E-mail: iza@iza.org
}

\begin{abstract}
Any opinions expressed here are those of the author(s) and not those of IZA. Research published in this series may include views on policy, but the institute itself takes no institutional policy positions. The IZA research network is committed to the IZA Guiding Principles of Research Integrity.

The Institute for the Study of Labor (IZA) in Bonn is a local and virtual international research center and a place of communication between science, politics and business. IZA is an independent nonprofit organization supported by Deutsche Post Foundation. The center is associated with the University of Bonn and offers a stimulating research environment through its international network, workshops and conferences, data service, project support, research visits and doctoral program. IZA engages in (i) original and internationally competitive research in all fields of labor economics, (ii) development of policy concepts, and (iii) dissemination of research results and concepts to the interested public.
\end{abstract}

IZA Discussion Papers often represent preliminary work and are circulated to encourage discussion. Citation of such a paper should account for its provisional character. A revised version may be available directly from the author. 


\section{ABSTRACT \\ Fighting Poverty: Assessing the Effect of Guaranteed Minimum Income Proposals in Québec}

This paper analyzes the impact of a recent recommendation made by Quebec's Comité consultatif de lutte contre la pauvreté et l'exclusion sociale to guarantee every individual an income equal to $80 \%$ of Statistics Canada's Market Basket Measure (MBM). Workers with earnings at least equivalent to 16 weekly hours at the minimum wage would be entitled to $100 \%$ of the MBM. We also investigate the impact of three alternative proposals: 1) a change in the above the hours cut-off from 16 to 30 hours; 2) a guaranteed income equal to $100 \%$ of the MBM, irrespective of earnings; 3 ) a $3 \$$ /hour conditional wage subsidy. To do this, we first estimate a structural labor supply model using the existing tax code and predict the labor supply of a representative sample of individuals based upon the parameter estimates of the model. Simulations show that the original recommendation would have strong negative impacts on participation rates of low-earners and that its cost would exceed $\$ 2$ billion. Increasing the hours cut-off is predicted to have little impact beyond those of the original recommendation. Providing a guaranteed income equivalent to $100 \%$ of the MBM, on the other hand, would have a large impact. We find that contrary to what is usually assumed, guaranteed income schemes may increase the incidence of low-income rather than decrease it.

JEL Classification: C25, D31, D63, H31, I30, J22

Keywords: Guaranteed Minimum Income, ex ante evaluation, labor market effects, financial cost, poverty alleviation, public finance

Corresponding author:

Jean-Yves Duclos

Department of economics

Pavillon de Sève

Université Laval

Québec, QC, G1V 0A6

Canada

E-mail: jyves@ecn.ulaval.ca 


\section{Introduction}

Over the past fifteen years, the Government of Quebec has introduced a number of relatively novel policies aimed at fighting poverty. The most comprehensive initiative has certainly been the enactment in 2002 of Bill 112, known as An Act to Combat Poverty and Social Exclusion. The Act is quite ambitious:

The object of this Act is to guide the Government of Québec and society as a whole towards a process of planning and implementing actions to combat poverty, prevent its causes, reduce its effects on individuals and families, counter social exclusion, and strive towards a poverty-free Québec.

Such an Act is unique in North America; it also constitutes a significant political innovation, if only because it makes poverty reduction an explicit and central policy priority. The Act also establishes A National Strategy to Combat Poverty and Social Exclusion and provides for the creation of an Anti-Poverty Fund ("Fonds québécois d'initiatives sociales"). It has further instituted an advisory committee known as the CCLP ("Comité consultatif de lutte contre la pauvreté et l'exclusion sociale"). The role of the CCLP is to advise the government on the planning, implementation and assessment of actions taken within the scope of the National Strategy. The CCLP may also make recommendations and give opinions on government policies that may have a direct or indirect impact on poverty and social exclusion.

In this context, the CCLP published in 2009 a report containing a series of interesting and important recommendations on the means of ensuring that all Quebecers have incomes that enable them to meet their basic needs Comité consultatif de lutte contre la pauvreté et l'exclusion sociale 2009). Two of these recommendations (to which we refer jointly as the "CCLP recommendation") are the focus of the present paper. They are singled out because they naturally lend themselves to analytical investigation and also because together they broadly amount to establishing a guaranteed minimum income. 
The purpose of this paper is thus to investigate the likely impact of the CCLP recommendation on the employment and income of the residents of the Province of Quebec. Naturally, the usual ex post approaches to program evaluation cannot be relied upon as the recommendation has not yet been implemented. Rather, we rely on what is known as ex ante evaluation in the literature. An ex ante evaluation involves simulating the impacts of hypothetical/new programs or forecasting the impacts of existing programs in new contexts. Typically these evaluations depend on a structural estimation of the parameters of a model (Todd and Wolpin 2006) or on a reduced form model derived from a specific structural model. ${ }^{1}$ The ex ante evaluation of a program then uses these behavioural parameters to estimate by how much behaviour would be expected to change if the program were implemented.

Ex ante evaluations are particularly useful in a program development phase to make informed decisions for extending the target population of an existing program. They also facilitate an optimal use of limited resources by ensuring that governments make financial investments in programs that are likely to have a useful impact. These evaluations are helpful in considering implementation of new programs and can also serve as complements to future ex post evaluations.

Ex ante evaluations differ from ex post evaluations in that the data are observed for only the "untreated" population. In this case, the counterfactual to be estimated is the set of outcomes for the population to be treated rather than for the controls. The key identification condition in this approach boils down to the program having an impact only through individual budget constraints. This is precisely why we focus on two specific "recommendations" made in the CCLP report: they both impact the individual budget constraints. To be more specific, the two recommendations we investigate are the following (see recommendations 2 and 13 in Comité consultatif de lutte contre la pauvreté et l'exclusion sociale 2009):

Recommendation 1 The CCLP recommends that, as a first step, baseline financial support be set at $80 \%$ of (Statistics Canada's) Market Basket Measure (MBM) for disposable income in municipalities with a population of fewer than 30,000 inhabitants.

Recommendation 2 The CCLP recommends that individuals who work an average of 16 weekly hours at the minimum wage have a disposable income that is no lower than the above Market Basket Measure for disposable income in municipalities with a population of fewer than 30,000 inhabitants. 
These recommendations (to which we refer jointly as the "CCLP recommendation") are the main focus of the paper because they were proposed by a government advisory committee and have the potential to become official policy. We nevertheless investigate three variants of the CCLP recommendation:

1. Change the $80 \%-100 \%$ MBM cut-off from 16 hours per week to 30 .

2. Raise the financial support to $100 \%$ of the MBM to everyone, irrespective of hours of work.

3. Provide a $3 \$$ hour subsidy to individuals who find a job and work at least 30 hours per week.

The first variant makes the CCLP recommendation somewhat less generous. It is equivalent to increasing the implicit tax rate on earnings. We will refer to this variant as "16-30 CO" in what follows. The second variant makes the CCLP recommendation somewhat more generous because the guaranteed minimum income is independent of hours of work. It will be referred to as "100\% MBM". Finally, the third variant, "AE-SSP", borrows from Action Emploi and the SSP and proposes to investigate the impact of a conditional $3 \$$ /hour wage subsidy.

Our strategy consists estimating a structural labor supply model using a representative sample of Quebec residents and in which the budget constraints are based upon the existing tax code. We next modify the budget constraints in accordance with the above original and modified proposals and simulate their likely long-term impact on employment and income using the parameter estimates of the econometric model.

Our results show that the original CCLP recommendation would have a large negative impact on hours of work and labor force participation - and mostly so among low-income workers. In addition, the CCLP recommendation would be rather costly. It would amount to additional outlays of the order of $\$ 2.2$ billions per year, of which $85 \%$ would be borne by the provincial government. Changing the cut-off from 16 to 30 hours is predicted to have little impacts beyond those of the original recommendation. Providing a guaranteed income equivalent to $100 \%$ of the MBM would, however, have a large impact. The total program outlay would amount to $\$ 3.7$ billion, almost twice as much as for the original CCLP recommendation. The behavioural reactions to the guaranteed minimum schemes are large enough so that more individuals end up with a lower income than in 
the absence of those schemes. Only the AE-SSP scenario has an unambiguously positive impact on labor supply and income.

\section{Policy, Data and Budget Constraints}

\subsection{Self-sufficiency and Employment}

As stressed in its Policy Statement (Gouvernement du Québec 2002), the Government of Quebec considers employment to be the primary road to independence and often the best way to combat poverty. The CCLP report and the government's statement are reminiscent of the debate on the competing objectives of providing sufficient income support to escape from material poverty while making work sufficiently attractive. Although social assistance typically provides low benefits (often insufficient to escape material poverty by most standards), in some circumstances it can represent an attractive alternative to low-paid work, especially for families with children. As stated by the Ontario Task Force on Income Security, "[a] modern income security system would expect and encourage individuals to assume personal responsibility for taking advantage of opportunities for engagement in the workforce or in community life" (Task Force on Modernizing Income Security for Working-Age Adults 2006, p.16). Longer-term receipt of social assistance can also reinforce poverty by deteriorating recipients' employment skills and by lowering their aspirations and morale. Parental use of social assistance can further increase the probability that their children will eventually be social assistance recipients (see Beaulieu et al. 2005 for evidence for Quebec).

Those governments that emphasize the importance of employment in combatting poverty have typically implemented so-called "in-work benefits" to encourage work. The Earned Income Tax Credit in the United States, the Working Tax Credit in the United Kingdom, and the Prime pour l'emploi in France are all examples

of policies that attempt to make work "pay". A Canadian "Working Income Tax Benefit" (WITB) was introduced in March 2007 and consists of a relatively modest refundable tax credit set to $20 \%$ of earned income up to $\$ 500$ for individuals and $\$ 1,000$ for families that is reduced by $15 \%$ of net income for individuals earning more than $\$ 9,500$ and families earning more than $\$ 14,500$. The WITB aims at improving the incentives to work for low-income Canadians and to lower the socalled "welfare wall". Alternatives to these programs have also been proposed. 
The Task Force on Modernizing Income Security for Working-Age Adults (2006) proposes to combine a Basic Refundable Tax Credit and a Working Income Benefit to all low-income working-age adults; such a program would offer a maximum benefit of around $\$ 4,000$ per year, which would begin to be clawed back at an income level of around $\$ 5,000$ per year and would be reduced to zero at income of $\$ 21,000$ per year. The benefit would not be available to those without earnings; Saunders (2005) has recently supported such a scheme.

There is a large consensus in the literature that policies that increase the incentives to work yield positive results (see,e.g. Keane 2011; Meghir and Phillips 2010; Meyer 2010). Men are usually found to be somewhat less responsive than women and single mothers to changes in the marginal tax rates. The decision of whether to take paid work is, however, quite sensitive to taxation and transfers for women and mothers in particular. Likewise, wage subsidies have also been found to yield interesting results in terms of participation. In Canada, evidence from studies evaluating the Self-Sufficiency Project (SSP; see Card and Hyslop 2005, Card and Hyslop 2009, Brouillette and Lacroix 2010) has shown that single mothers can respond strongly to a generous wage subsidy. Similar results have been found in Quebec where the Action Emploi program closely mimics the SSP setup (Brouillette and Lacroix 2011).

Because labor supply appears to be sensitive to taxation and subsidies, it is useful to investigate CCLP's sweeping recommendation prior to their being implemented. Before we turn to formal modelling, we discuss the data upon which our analysis is based and we graphically depict how the recommendation changes the individual budget sets.

\subsection{Sample Characteristics}

Our analysis uses data primarily drawn from Statistics Canada's Social Policy Simulation Database (SPSD/M) for 2004. SPSD/M provides a statistically representative database of individuals in their family context, with enough information on each individual to compute taxes paid to and cash transfers received from governments. The main component of the database is the Survey of Labor and Income Dynamics (SLID). Important variables that are unavailable in the SLID are imputed by Statistics Canada using the Survey of Household Spending (SHS) and administrative data. For the specific purposes of this study, additional variables 
such as the net value of residence, the value of financial assets and the net worth of the vehicles owned have also been imputed using the Survey of Financial Security of 2005 and Census data for $2001 .^{2}$

Our sample omits individuals under 18 and over 65 years of age as well as full-time students and the disabled. Individuals reporting earnings from self-employment and those working on average more than 70 hours per week are also excluded from the sample. Overall, the sample consists of 3,031 individuals. The labor supply model is estimated for three distinct sub-groups: single men, single women, and single mothers. ${ }^{3}$ Table 1 reports descriptive statistics on key variables included in the econometric model. The patterns reported in the table are roughly consistent with those found in the census data, e.g., single men are on average younger than both single women and single mothers. In addition, they tend to work more and earn a higher hourly wage rate. As a consequence, their earnings are also higher than those of the other groups. Single mothers in our sample have on average 1.72 children and $18 \%$ have preschoolers. The bottom panel of the table reports the sample weights of each sub-group along with their respective census weights to assess the representativeness of our sample. Single women and single mothers are somewhat under-represented in our sample, whereas the opposite holds for single men. The discrepancies are partly attributable to relatively small sample sizes but also to the fact that the algorithm used to generate our sample could not be strictly applied to the census data.

Table 1: Descriptive Statistics

\begin{tabular}{|c|c|c|c|c|c|c|}
\hline \multirow[t]{2}{*}{ Variables } & \multicolumn{2}{|c|}{ Single men } & \multicolumn{2}{|c|}{ Single women } & \multicolumn{2}{|c|}{ Single mothers } \\
\hline & Mean & Std-dev & Mean & Std-dev & Mean & Std-dev \\
\hline Age & 38.08 & 11.23 & 43.12 & 13.29 & 40.96 & 8.13 \\
\hline Weekly hours of work & 34.51 & 13.70 & 27.53 & 15.73 & 28.02 & 14.86 \\
\hline Earnings $(\$ 1000)$ & 43.42 & 66.23 & 23.42 & 34.86 & 21.45 & 16.84 \\
\hline Non-labor earnings $(\$ 1000)$ & 4.39 & 32.60 & 3.57 & 10.01 & 3.01 & 4.86 \\
\hline Hourly wage rate $(\$)$ & 16.51 & 5.14 & 14.50 & 4.09 & 14.75 & 3.99 \\
\hline \# Children 0-18 & & & & & 1.72 & 0.95 \\
\hline Have preschool children & & & & & 0.18 & 0.38 \\
\hline Sample size & \multicolumn{2}{|c|}{1809} & \multicolumn{2}{|c|}{831} & \multicolumn{2}{|c|}{391} \\
\hline Sample weights & \multicolumn{2}{|c|}{385962} & \multicolumn{2}{|c|}{265469} & \multicolumn{2}{|c|}{100669} \\
\hline Census weights & \multicolumn{2}{|c|}{327246} & \multicolumn{2}{|c|}{291841} & \multicolumn{2}{|c|}{186966} \\
\hline
\end{tabular}

\subsection{Budget Constraints}

In order to understand the likely impact of the CCLP recommendation and its variants, it is useful to depict graphically how they change the budget set of representative individuals. The budget sets are computed using the Canadian Tax and 


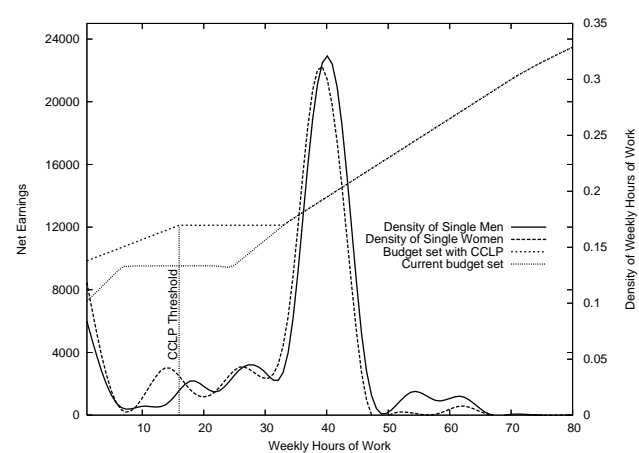

(a) Single Males and Females With No Assets

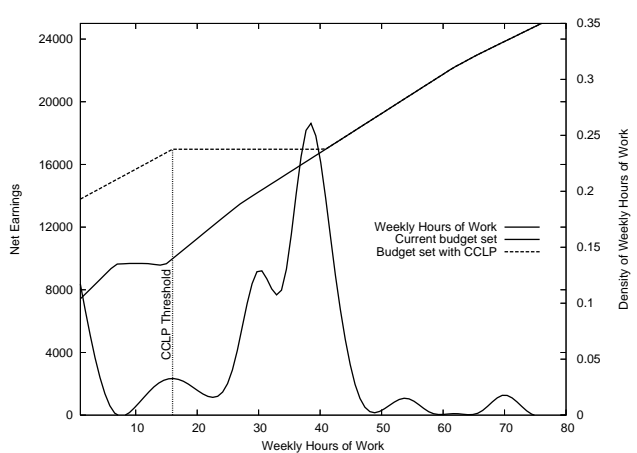

(b) Single Mothers with Median Assets

Figure 1: Budget Sets for Singles and Single Mothers, with and without CCLP benefits

Credit Simulator (CTaCS) developed by Milligan (2008). CTaCS simulates the Canadian personal income tax and transfer system (provincial and federal). The program was slightly modified to take into account Quebec's 2004 welfare benefits (Gouvernement du Québec 2004). ${ }^{4}$ For the sake of simplicity, we assume that the CCLP benefits would not be taxable at the federal level nor at the provincial level, and that no Employment Insurance or Quebec Pension Plan premia would be levied against these benefits.

\section{CCLP Budget Sets}

Figure 1(a) plots the yearly net earnings of single males and single females with no assets, while Figure 1(b) focuses on single mothers with median assets. ${ }^{5}$ Both figures are drawn under the assumption that workers earn the minimum wage and work full-year at some weekly hours of work shown on the horizontal axis.

The dotted lines in both figures depict the budget sets under existing social assistance programs. The solid lines are the budget sets derived from the CCLP recommendation. The figures also plot the (weighted) densities of work hours based on our sample data. In both figures, the densities peak at approximately 40 hours, although single mothers have a bimodal distribution with another peek at 30 weekly hours of work. The hours distribution highlights the fact that the majority of singles would have a strong incentive to reduce their hours of work. Even those whose earnings are higher than the cut-off point could still prefer to work less and earn less than they currently do.

Figure 1(a) focuses on single men and women. The budget set is identical for 


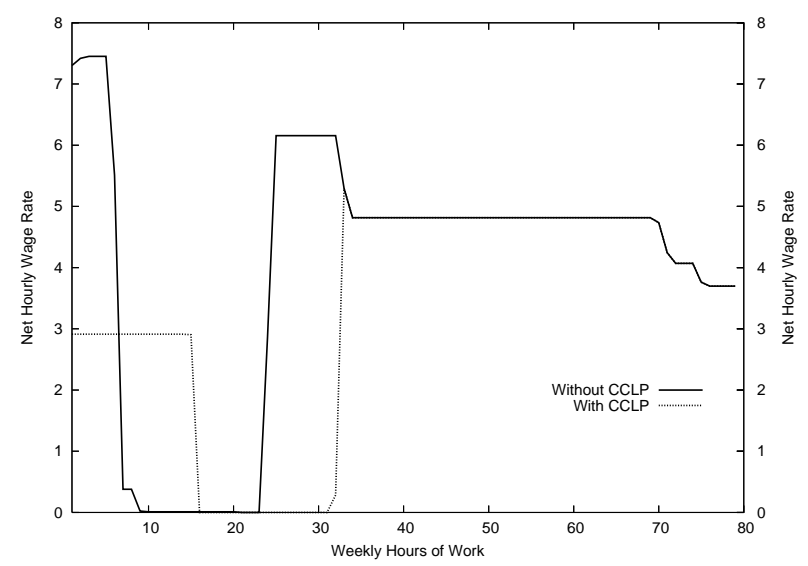

Figure 2: Net Hourly Wage Rate, Minimum Wage Worker, No Assets

both groups because it is drawn under the same assumptions (minimum wage, no assets, etc.). Notice first that inactive individuals would gain under the CCLP recommendation. Indeed, they would receive a transfer equivalent to $80 \%$ of the MBM which is substantially more than the welfare benefits that prevailed in 2004 . As they start working, their net earnings increase slowly because government transfers decrease fast. As they reach 16 hours per week, workers face an implicit tax rate of $100 \% .{ }^{6}$ Beyond 32 weekly hours of work they are no longer entitled to the transfer and they face the standard tax system. Under the existing system, net earnings increase faster than under the CCLP recommendation at first due to the earnings disregard in the determination of welfare benefits. A plateau is reached as early as 7 hours of work per week because welfare benefits are taxed at an implicit rate of $100 \%$ beyond the corresponding earnings.

Figure 1(b) depicts the budget sets and the distribution of weekly hours of work of single mothers with median-level net assets and earning the minimum wage rate. Under the current welfare regime their monthly benefits are relatively low because they are means-tested. Under the CCLP regime, single mothers would enjoy a considerable increase in earnings.

To gain a better understanding of the implicit incentive effects in both the CCLP and the status quo worlds, Figure 2 sketches the net hourly wage rate a single female earning the gross minimum wage and with no assets would enjoy as she increases her weekly hours of work. In the current world, the income disregard in the welfare 
system ensures a recipient's earnings are not taxed away at low hours of work. She thus enjoys a net wage rate of $\$ 7.45$ /hour. As her earnings increase beyond the disregard, every additional dollar of earnings decreases her welfare benefits by one dollar. She thus earns a net wage rate of $\$ 0 /$ hour. Once her earnings completely exhaust her benefits, she starts paying income taxes and thus enjoys a net wage rate of about $\$ 6 /$ hour. Finally, as her earnings increase beyond the first income tax bracket, she starts paying yet more taxes and works for a net wage rate of about $\$ 5 /$ hour as a result.

In the CCLP world, the first hour of work increases earnings by as little as $\$ 2.91$ because the transfer received from the government decreases at a constant rate between $80 \%$ of the MBM at zero hours of work and $100 \%$ of the MBM at 16 hours of work. Subsequently, as she works beyond 16 hours of work per week, she receives a net wage rate of $\$ 0 /$ hour. Only once she reaches 32 hours per week is her net wage rate again positive. This is because her earnings at 32 hours per week are just equal to $100 \%$ of the MBM. Working in excess of 32 hours per week brings her beyond the threshold and she no longer receives any transfer. Her earnings are then large enough for her to pay income taxes.

The CCLP recommendation does not remove the "welfare trap" per se. They simply shift it rightwardly and as a consequence changes the incentive effects at low hours of work.

\section{Variants of CCLP Budget Sets}

The 16-30 $C O$ and $A E-S S P$ variants are based upon recent policies that were either implemented in Québec or were part of demonstration projects conducted in British Columbia. Indeed, both the Self-Sufficiency Project (SSP, in British Columbia) and the Action Emploi program (AE, in Québec) required welfare participants to work at least 30 hours per week to qualify for an income subsidy. The AE program provided a $3 \$$ /hour subsidy whereas the SSP project was somewhat more generous. $^{7}$ The $100 \% M B M$ corresponds more closely to what is usually thought of as a universal guaranteed income.

Figure 3 illustrates the budget sets of the CCLP recommendation along with the three variants we consider. The figure is drawn for single mothers with median asset values (the hours distribution is not depicted for ease of reading).

As before the solid line represents the current welfare system. The CCLP recommendation corresponds to the budget set that originates at $13,573 \$$ and peaks at 


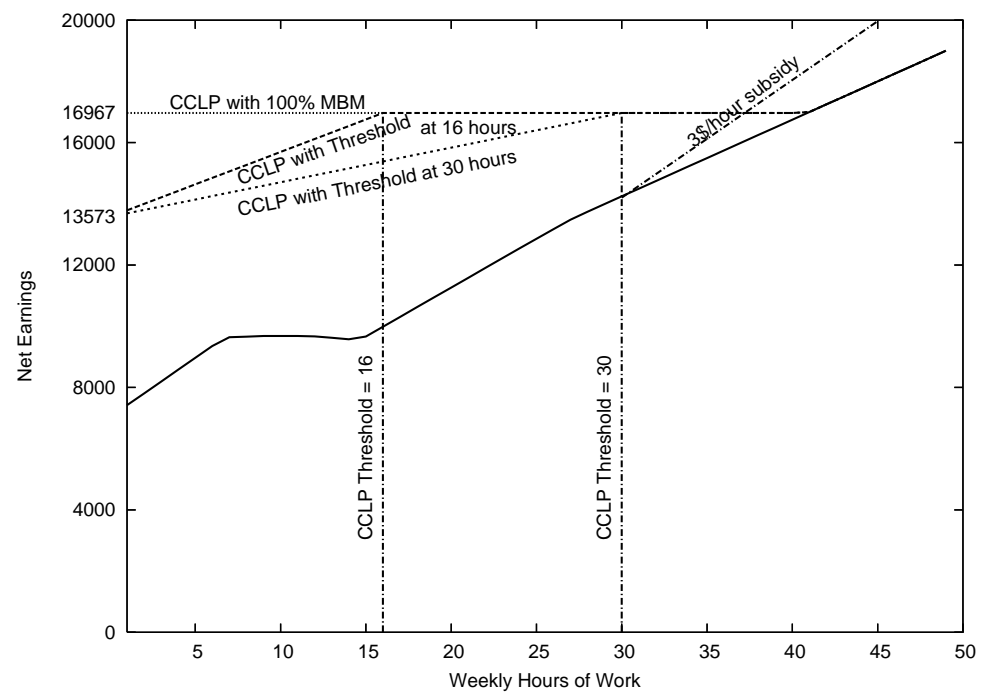

Figure 3: CCLP and modified CCLP Budget Sets

$16,967 \$$ at 16 hours of work per week. The $16-30 C O$ scenario consists in moving the threshold to qualify for $100 \%$ of the MBM from 16 to 30 hours. This results in rotating the budget line clockwise and thus makes the new policy less attractive financially. Under the $100 \% M B M$ scheme everyone is entitled to income equivalent to $100 \%$ of the MBM, irrespective of work effort. This is illustrated by the horizontal line that starts at a level of income of $16,967 \$$. Variant 3 is a $3 \$ /$ hour subsidy conditional on working at least 30 hours per week. The subsidy is offered only to those that do not work and can thus have only a positive impact at the so-called extensive margin - that is, on the decision to work or not. The decision to work boils down to a comparison between the utility level at zero hours of work with that accruing at 30 hours of work or more.

The behavioural responses to the different schemes are complex and hard to predict a priori. In some cases, they can be signed unambiguously but their magnitude cannot be ascertained easily because they depend upon potential wage rates as well as on observed and unobserved individual characteristics. We must therefore rely upon a structural econometric model to estimate their likely impact. In the next section, we briefly sketch the econometric approach we use to estimate the model. Interested readers can find the technical details in Appendix A. 


\section{Econometric Model}

Individuals are assumed to maximize a well-behaved utility function defined over leisure, $l$, and net income, $y$, with respect to time and income constraints:

$$
\max U^{i}\left(l^{i}, y^{i}\right) \quad \text { s.t. } \quad y^{i} \leq y^{i}\left(l^{i}, w\right) \quad \text { and } \quad l^{i} \leq T
$$

where index $i$ corresponds to a specific level of leisure defined as $l^{i}=T-h^{i}$, where $T=80$ is the time endowment, and where $h^{i}$ is weekly hours of work. ${ }^{8}$ Net income equals earnings, $w h^{i}$, plus exogenous non-labor income, $N$, and government transfers, $B$, less income taxes, $T$ (Keane and Moffitt 1998):

$$
y^{i}\left(h^{i}\right)=w h^{i}+N+B\left(w h^{i}, N, X\right)-T\left(w h^{i}, N, X\right)
$$

where $X$ is a vector of demographic variables and $w$ is the hourly wage rate. Following convention, we assume that preferences can be approximated by a translog utility function. Heterogeneity in preferences is accounted for by conditioning the utility function, equation (3.1), on age, number of children in the household and presence of preschoolers (single mother households).

Preference for leisure is also allowed to vary with unobserved characteristics. The latter are proxied by a random component that is assumed to be independently and identically distributed as a normal random variate. In addition, optimization errors are introduced into the utility function through another random component that is assumed to follow a Type-I extreme value distribution. This assumption is made to allow for the possibility that the individual optimal choice of labor supply may not correspond exactly to the discrete choices we specify in the model.

Finally, the literature on discrete labor supply models has generally found that the above model tends to under predict the number of individuals with $h=0$ or $h=40$. This will occur if the "fixed costs" associated with work (commuting, daycare, etc.) are not accounted for explicitly (see, e.g. Cogan 1981). These costs

are difficult to measure but may be proxied by demographic variables. To account for bunching at 40 hours of work, we introduce in the utility function a dummy indicator that is equal to one if $h=40$. The parameter associated with this dummy variable will be positive if individuals value working that many hours and will be negative otherwise.

Given the above assumptions, it can be shown that the probability of working 
$h^{i}$ hours of work per week is given by:

$$
\operatorname{Pr}\left[h^{i}\right]=\int \frac{\exp \left(U^{i}\left(l^{i}, y^{i}\right) \mid v\right)}{\sum_{j=1}^{p} \exp \left(U^{j}\left(l^{j}, y^{j}\right) \mid v\right)} \phi(v) d v,
$$

where $\phi$ is the normal density function of the unobserved preferences, $v$. The ratio of exponential functions derives from assuming that the optimization errors follow a Type-I extreme value distribution.

\section{Estimation and Simulation Results}

\subsection{Estimation Results}

The parameter estimates of the labor supply model of the three samples are presented in Table 2. The parameters for the three samples are compatible with the required quasi-concavity of the preferences, either globally or locally ${ }^{9}$ : this is the case for $100 \%$ of single males and females and for $94.37 \%$ of single mothers. Furthermore, net income is found to be a normal good for $100 \%$ of single females, $98.19 \%$ of single mothers, and $96.47 \%$ of single males. ${ }^{10}$ It thus appears that, for the majority of the individuals in our samples, hours of work can legitimately be represented as the outcome of the maximization of utility under a budget constraint.

As a check on the overall fit of the model, we report observed and predicted distributions of hours of work for the three samples separately in Figures 4(a)- 4(c). For each individual we compute the budget constraint based upon his/her characteristics. $^{11}$ Next, we compute the utility associated with each discrete point of his/her budget constraint. ${ }^{12}$ The discrete point that yields the highest utility level is then selected. The figures show that the model does a good job at predicting observed outcomes. Indeed, the differences between observed and predicted choices are small for each sample. In particular, the fit at zero [0,4[ and at [36,44[ and $[35,45[$ is almost perfect. Since the parameter estimates for the three samples are consistent with a priori expectations and since nearly all individuals behave consistently with basic economic theory, we proceed to simulate the expected impact of the CCLP recommendation and of its variants with some confidence. 


\subsection{Simulation Results}

The simulation exercise follows the strategy that was outlined in the previous section. Individual budget sets are computed in accordance with the proposals and based upon individual characteristics using CTaCS. Net income is computed for each discrete point of the budget constraint. Finally, the utility level of each point is computed and the one that yields the highest utility is selected (taking into account the distribution of the different random terms).

\subsubsection{Simulation of the CCLP recommendation}

The upper panel of each section of Table 3 reports the impact on weekly hours of work of the CCLP recommendation. The 2004's hours distribution is presented in the last column of the table. Thus, for example, $11.63 \%$ of single men worked between [0,4[ hours per week in 2004, and hours as many as 56.24\% worked between [36,44[ hours per week. The hours distribution following the CCLP recommendation is shown at the bottom of the upper panel of each section of Table 3 . Hence, after the reform, $25.34 \%$ of single men would work between $[0,4[$ hours per week.

The expected hours distribution following the implementation of the recommendation is reported column-wise. The matrices thus decompose the total change in the hours distribution into its different components. Numbers above the diagonal correspond to an increase (in percentage points) in weekly hours of work following the implementation of the CCLP recommendation, whereas the converse holds for numbers below the diagonal.

For single men, a comparison between the diagonal elements with those of the rightmost column reveals an important change in the hours distribution: the share of workers reporting between 36 and 44 hours per week would decrease from $56.24 \%$ to $43.85 \%{ }^{13}$ For these workers, the decrease in full-time work would translate into a larger share of non-participation $(+9.98 \%$ in the $[0,4[$ hours bracket $)$ and an increase in the $[4,12[$ bracket $(+1.85 \%)$. The difference in hours of work is reported in the line entitled "Change". There we see that the the CCLP recommendation would increase overall non-participation by 13.77 percentage points. Basically no change is reported above the diagonal of the matrix. This is not surprising given that the CCLP recommendation offers little incentive to increase weekly hours of work. 
The results for single women are very similar to those of single men except for the fact that the changes in the hours of work distribution is more evenly spread out. The overall increases in the $[0,4[$ and $[4,12[$ brackets $(+12.64 \%$ and $+1.93 \%$, respectively) are associated with overall decreases in the [28,36[ and [36,44[ brackets $(-2.68 \%$ and $-10.69 \%$, respectively). Just as in the above section of Table 3 , very little is reported above the diagonal, and thus the CCLP's recommendation is predicted to have a significant negative impact on the labor supply of single females.

The simulations for single mothers are not reported for the sake of brevity. ${ }^{14}$ They show that the changes in the hours distribution are small and that none is statistically significant, save for the $[35,45$ [ bracket. This is not surprising given that only single mothers who have significant assets are predicted to be impacted by the recommendation. For the $[35,45$ [ bracket, the share of full-time work is predicted to decrease by 4.34 percentage points, much less than what is predicted for single males and females. This is because although the majority of single mothers $(80 \%)$ in our sample have net positive assets, in only $45 \%$ of cases are these assets large enough to decrease single mothers' entitlement to social welfare benefits. In addition, only $37 \%$ of the single mothers in our sample would be entitled to yearly CCLP benefits larger than $100 \$$.

Table 4 goes one step further and reports the impact of the recommendation on the expected weekly hours of work with respect to percentiles of net earnings. ${ }^{15}$ It also distinguishes between the intensive margin, i.e. the impact on hours of work conditionally on working, and the extensive margin, i.e. the impact on participation per se. The table reveals a number of interesting results. To start with, most of the behavioural adjustments occur at the extensive margin, as shown in the first column. These results are entirely consistent with the recent literature on income taxes and labor supply (see, e.g., Blundell 2000, Eissa and Hoynes 2006, Meyer 2002). Thus, conditional on working, individuals decrease their weekly hours of work very little. Many choose, however, to stop working altogether. This response varies considerably with net earnings. According to Table 4 , individuals in the bottom 10 and 25 income percentiles react most in percentage terms, while those in the upper percentiles react less, especially at the intensive margin. All behavioural adjustments at both the intensive and extensive margins are statistically different from zero. 


\subsubsection{Simulation of CCLP Variants}

The 16-30 CO rotates the budget set clockwise (see Figure 3), thus making work less attractive for those out of employment (extensive margin), while simultaneously increasing the incentives to decrease hours for those already working (intensive margin). The results are reported in the lower panel of each section of Table 3 . The simulations results show that labor supply is almost identical to what would arise under the CCLP recommendation. Because of the similarity between the two schemes, and for the sake of brevity, we do not report the entire transition matrices but focus on the total changes in hours of work under this scenario. For each population considered, the model predicts there will be fewer active individuals, and consequently more unemployed individuals.

The simulations results of the $100 \% M B M$ and $A E-S S P$ schemes are reported in Table 5. Each section of the table is divided into two panels. The upper panels report the transition matrices that would be observed under $100 \% M B M$, while the lower panels focus on the impact of $A E-S S P$. The model predicts that the $100 \%$ MBM scheme would have very large effects on the labor supply of single males and females alike. In both cases, the proportions of full-time workers would decrease by as much as 17.7 and 14.7 percentage points, respectively. The overall increase in non-participation would be 22.0 and 19.4 percentage points respectively. Nearly every level of hours of work decrease in favour of non-participation and the $[4,12]$ bracket. This behavioural adjustment arises because the $100 \%$ MBM scheme generates a (negative) income effect on labor supply. The negative reaction is no surprise. The magnitude of the response is somewhat surprising. Single mothers (not reported, see online appendix) reduce their labor supply much less because the $100 \%$ MBM transfer is not much different from the welfare benefits to which they are already entitled.

The $3 \$$ /hour wage subsidy, as expected, increases the labor supply of each group considered in Table 5. Overall, non-participation among single men decreases by 3.3 percentage points, whereas it decreases by 4 percentage points among single women and single mothers. The magnitude of the response is surprisingly close to that found by Brouillette and Lacroix (2011). Brouillette and Lacroix (2011) analyze the impact of the Action Emploi program referred to in the introduction, which offers a $3 \$$ /hour subsidy to welfare recipients who find a full-time work (30 hours or more). Action Emploi is estimated to have decreased non-participation by 
single mothers by anywhere between 4.2 and 6.6 percentage points. Our structural model generates very similar results despite the fact that it is an ex ante exercise and despite the fact that it rests upon an entirely different set of assumptions, model and data. The fact that this structural model is able to replicate well the

findings of Brouillette and Lacroix (2011) would seem to provide further credence to our simulations.

\subsection{The Cost of the CCLP recommendation}

All in all, our simulation results show that single males and females would react strongly to the CCLP recommendation. Furthermore, our simulations also show that those that would respond most are precisely those that have the lowest current earnings. The sharp decreases in participation rates and ensuing decreases in income taxes, coupled with sizeable outlays, may make the CCLP recommendation costly. We now turn to this issue.

In addition to the CCLP benefits per se, the CCLP costs to the federal and provincial governments must take into account changes in income taxes, transfers, social assistance benefits, Quebec Pension Plan and Employment Insurance premiums, etc. These changes are computed under two different scenarios. In the first, the accounting scenario, we assume that the labor supply response following the implementation of the CCLP recommendation is null. In the second, the behavioural scenario, we allow for such a response. In both cases, we start by computing the taxes and transfers of each individual in our sample based on their observed labor supply. We next modify the budget constraints according to the CCLP recommendation and compute the taxes and transfers again. The differences are then multiplied by the individual sample weights to obtain an aggregate estimate of the cost of the two scenarios.

Table 6 reports the detailed costs associated with both scenarios. The upperhalf panel concerns the accounting scenario. Recall that we assume that the CCLP benefits would not be taxable at the federal nor at the provincial levels, and that no Employment Insurance or Quebec Pension Plan premiums would be levied against those benefits. ${ }^{16}$ In the case in which federal taxes would be levied against the CCLP benefits, the latter would have to be increased so that the net income accruing to the individual would meet the CCLP income objectives. Those additional CCLP expenses would represent an additional cost for the provincial government 
and additional revenues for the federal government. From a joint provincial-federal fiscal perspective, the overall cost of the CCLP recommendation would, however, not be altered were the benefits to be taxed at the federal level.

The upper panel of Table 6 represents the additional cost the provincial government would have to bear in order to implement the CCLP's recommendation. The amounts are in addition to the standard welfare benefits. Many more individuals would receive CCLP benefits than there are welfare recipients. Consequently, the additional amounts are sizeable. The per capita cost of the recommendation would vary between $\$ 500$ and $\$ 700$ per individual, and are slightly larger for single women.

The lower panel of Table6 6 reports the results of the behavioural scenario. Federal and provincial income taxes decrease because many individual decrease their labor supply in response to the CCLP benefits. Social assistance payments increase for the same reason: those who reduce their hours of work substantially or completely often become entitled to welfare benefits. The CCLP payments thus correspond to the additional outlays the government must bear to meet the requirements of the CCLP's recommendation. They are larger than in the accounting scenario because many individuals are expected to decrease their labor supply sufficiently to qualify for the benefits. The overall cost of the recommendation is predicted to be important: approximately $\$ 2,870$ per individual, which is more than four times the per capita cost of the accounting scenario. The total CCLP costs would then be of the order of $\$ 2.2$ billion, $85 \%$ of which would be borne by the provincial government. The remaining $\$ 331$ million would be borne by the federal government, $\$ 286$ million of which through a decrease in personal income tax revenue.

Table 7 reports the overall cost of the CCLP recommendation along with those of 16-30 CO, 100\% MBM and AE-SSP. We also indicate for each sample and for each case the proportions of individuals whose net income would increase, decrease or remain constant. Were the CCLP's recommendation implemented, the simulations indicate that slightly more would individuals would see their income decrease. This result is entirely driven by behavioural adjustments: non-participants benefit from an increased income whereas those who decrease their labor supply do so at the cost of lower income. As mentioned above, increasing the hours cut-off from 16 to 30 hours of work is predicted to have little behavioural impact. Consequently, the costs associated with this proposal are almost identical to those of the original CCLP recommendation. On the other hand, providing each individual with $100 \%$ 
of the MBM has a very large impact, both in terms of labor supply behaviour and income distribution. The overall cost of such a measure would amount to more or less $\$ 3.7$ billions, almost twice the cost of the original CCLP recommendation. In addition, proportionately more individuals would see their income decline due to a decrease in their labor supply. Finally, the table also shows the impact of providing a conditional wage subsidy. This proposal is aimed at a specific group of individuals and does not cause a negative income effect. It is consequently the least expensive measure and has a purely positive impact on the incomes of the targeted group. The federal government would even benefit from such a measure, since federal income taxes would increase and federal transfers would fall.

\section{Conclusion}

Guaranteed minimum income schemes are often proposed as a means to help reduce poverty. Yet, such schemes can generate important labor supply reactions due to built-in disincentives. The starting point of the paper stems from two recommendations (jointly termed the "CCLP recommendation") that were recently made by Quebec's Comité consultatif de lutte contre la pauvreté et l'exclusion sociale, and that have the potential to become official policy. Under the proposed recommendation, every individual would be guaranteed an income equivalent to $80 \%$ of the Market Basket Measure. Workers with earnings at least equivalent to 16 weekly hours paid at the minimum wage would be entitled to $100 \%$ of the Market Basket Measure (MBM).

To assess the potential impact of the CCLP recommendation, we first estimate a structural labor supply model using the existing tax code and a representative sample of the population of Quebec. We next simulate the impact of the recommendation by modifying the budget sets according to the CCLP recommendation and by predicting the labor supply of our representative sample based upon the parameter estimates of the labor supply model. The results show that the proposed scheme would have strong negative impacts on labor market participation rates, and mostly so among low wage workers.

In a world without labor market adjustments, the CCLP scheme is estimated to cost approximately $\$ 460$ million. When labor supply effects are accounted for, the cost increases to well above $\$ 2$ billion, due to recommendation's effects on transfers and forgone taxes at the provincial and federal levels. The bottom line is therefore 
that such schemes may introduce significant negative labor market effects, and that their cost may be considerably underestimated if these disincentive effects are assumed away.

An important benefit of using a structural model is that other schemes can be simulated and compared to the original recommendation. We consider three variants to the CCLP recommendation: 1) a change in the hours cut-off from 16 to 30 hours of work per week to qualify for the full MBM guaranteed income; 2) a guaranteed income equivalent to $100 \%$ of the MBM, irrespective of labor supply; 3) a $3 \$$ /hour wage subsidy to those unemployed individuals who find a full-time job (30 hours/week or more). The financial and behavioural impacts of the three proposals are estimated and contrasted to those of the CCLP recommendation. The simulation exercises show that changing the hours cut-off has very little impact both financially and in terms of labor supply relative to what is predicted under the CCLP recommendation. Providing a guaranteed income equivalent to $100 \%$ of the MBM has, however, a major impact both on work and on costs. The conditional wage subsidy has a positive impact on the income and on the labor supply of the unemployed. Because it is more focused than the other proposals, its fiscal impact is also more limited.

Guaranteed minimum income schemes are often analyzed within an "accounting" framework. That is, behavioural adjustments are often omitted because it is implicitly assumed that individuals do not react to financial incentives, or because modelling individual behaviour is a relatively demanding task that - so it is believed or hoped - may not change much the conclusions of the "accounting" approach. In this paper, we find that such behavioural adjustments are important. They matter for two reasons. First, omitting labor supply adjustments leads to a serious underestimation of the costs of the proposals. Second, the magnitude of the adjustments can be large enough so that more individuals end up with a lower income than in the absence of a guaranteed minimum income scheme. If the intention is to help individuals exit poverty, an efficient policy, from our model's perspective, would be to provide unemployed individuals a wage subsidy, not an unconditional income transfer. There is also mounting evidence on the efficacy of such policies in Canada and elsewhere.

An issue that has not been addressed in this paper concerns the public finance burden of financing the different schemes we have considered. The overall costs of the schemes vary between 2.1 and 3.7 billion dollars. Financing such large programs 
would necessarily require that taxes be raised. This would in all likelihood lead to yet larger labor supply adjustments. The costs reported in this paper are therefore probably conservative. We leave this issue open for future research. 


\section{Notes}

${ }^{1} \mathrm{~A}$ more recent reformulation (Todd and Wolpin 2008) builds on Ichimura and Taber (2000) and illustrates the use of reduced-form estimation of behavioural models in the evaluation of social programs without specification of functional forms.

${ }^{2}$ The details of the imputations are not presented for the sake of brevity but are available upon request.

${ }^{3}$ Single fathers are not included because there are too few of them in the sample.

${ }^{4}$ Welfare benefits are means tested. A number of variables need to be imputed in order to determine potential welfare benefits such as net property value (home and car) and the net value of financial assets. They are imputed based on auxiliary regressions using Statistics Canada's 2005 Survey of Financial Security.

${ }^{5}$ The CCLP recommendation made single mothers without assets worse off. It was agreed with members of the CCLP that for these households the budget set would remain as under the status quo.

${ }^{6}$ We acknowledge that the CCLP recommendation could be interpreted in slightly different ways with respect to the structure of the withdrawal rates of CCLP benefits as income increases. Our interpretation was validated by members of the CCLP through personal conversations.

${ }^{7}$ The AE program was implemented for a single year in 2002 and those who qualified were entitled to a (declining-with-years) wage subsidy during three years (see Brouillette and Lacroix 2011). AE has since been replaced by the Prime au Travail program which is more akin to a negative income tax.

${ }^{8}$ According to Gong and van Soest (2002), the parameter estimates are relatively insensitive to a particular normalization of $T$.

${ }^{9}$ Our specification is such that the preferences are quasi-concave whenever $u_{l l} u_{y}^{2}+u_{y y} u_{l}^{2}<0$, where $u_{l l}$ is the second-order derivative of $u$ with respect to $l, u_{y}$ is the first-order derivative of $u$ with respect to $y$, and where $u_{y y}$ is the second-order derivative of $u$ with respect to $y$.

${ }^{10} \mathrm{Net}$ income is normal if $u_{l l} u_{y}<0$. See Appendix A for a discussion of the parameter estimates.

${ }^{11}$ Age, hourly wage rate, net assets, etc.

${ }^{12}$ The number of discrete points differs between samples to reflect the empirical distribution of weekly hours of work and to ensure there are enough sample points at each point.

${ }^{13}$ Most estimates are statistically significant. To avoid cluttering the table, we only indicate those that are not statistically significant at the $10 \%$ threshold.

${ }^{14}$ They are available in the online appendix.

${ }^{15}$ The table reports the expected number of hours of work, not the distribution of the discrete hours of work as in previous tables.

${ }^{16}$ Because of this, the CCLP benefits correspond to the amount over and above the standard welfare benefits that are needed to meet the Market Basket Measure target. 


\section{References}

Beaulieu, Nicolas, J.-Y. Duclos, Bernard Fortin, and Manon Rouleau (2005) 'Intergenerational reliance on social assistance: Evidence from canada.' Journal of Population Economics 18(3), 539-562

Blundell, Richard (2000) "Work Incentives and "In-Work" Benefit Reforms : A Review.' Oxford Review of Economic Policy 16(1), 27-44

Brouillette, Dany, and Guy Lacroix (2010) 'Heterogeneous treatment and selfselection in a wage subsidy experiment.' Journal of Public Economics 94, 479 492

_ (2011) 'Assessing the impact of a wage subsidy for single parents on social assistance.' Canadian Journal of Economics/Revue canadienne d'économique 44(4), 1195-1221

Card, David, and Dean R. Hyslop (2005) 'Estimating the effects of a time-limited earnings subsidy for welfare-leavers.' Econometrica 73(6), 1723-1770

Card, David, and Dean R. Hyslop (2009) 'The dynamic effects of an earnings subsidy for long-term welfare recipients: Evidence from the self sufficiency project applicant experiment.' Journal of Econometrics 153(1), 1-20

Cogan, J. (1981) 'Fixed cost and labour supply.' Econometrica 49, 945-964

Comité consultatif de lutte contre la pauvreté et l'exclusion sociale (2009) 'Advisory opinion on individual and family income improvement targets, on optimal means for achieving them, and on baseline financial support.' Technical Report, Government of Quebec

Eissa, N., and H. Hoynes (2006) 'Behavioral responses to taxes: Lessons from the EITC and labor supply.' Tax Policy and the Economy 20, 74-110

Gong, X., and A. van Soest (2002) 'Family structure and female labour supply in Mexico City.' Journal of Human Resources 37, 163-191

Gouriéroux, C., and A. Monfort (1996) Simulation-Based Econometric Methods Core Lectures (Oxford University Press)

Gourriéroux, C., and A. Monfort (1991) 'Simulation based econometrics in models with heterogeneity.' Annales d'économie et de statistique 20(1), 69-107 
Gouvernement du Québec (2002) 'The will to act, the strength to succeed.' National Strategy to Combat Poverty and Social Exclusion

Gouvernement du Québec (2004) 'Règlement sur le soutien du revenu, R.Q. c. s-32.001, r.1'

Ichimura, Hidehiko, and Christopher R. Taber (2000) 'Direct estimation of policy impacts.' NBER Technical Working Papers 0254, National Bureau of Economic Research, June

Keane, M., and R. Moffitt (1998) 'A structural model of multiple welfare program participation and labor supply.' International Economic Review 39(3), 553-589

Keane, Michael P. (2011) 'Labor supply and taxes: A survey.' Journal of Economic Literature 49(4), 961-1075

Meghir, Costas, and David Phillips (2010) 'Labour supply and taxes.' In Dimensions of Tax Design: The Mirrlees Review, ed. Institute for Fiscal Studies (Oxford University Press) chapter 3, pp. 202-274

Meyer, Bruce D. (2002) 'Labor supply at the extensive and intensive margins: The EITC, welfare, and hours worked.' The American Economic Review 92(2), 373379

Meyer, Bruce D. (2010) 'The effects of the EITC and recent reforms.' In Tax Policies and the Economy, ed. Jeffrey R. Brown, vol. 24 (Cambridge: MIT Press) pp. $153-180$

Milligan, K. (2008) 'Canadian Tax and Credit Simulator. Database, software and documentation.' Technical Report, University of British Columbia

Saunders, Ron (2005) 'Lifting the boats: Policies to make work pay.' Vulnerable Workers Series 5, Canadian Policy Research Networks, Ottawa

Soest, A. Van, and M. Das (2001) 'Family labor supply and proposed tax reforms in the Netherlands.' De Economist 149, 191-218

Task Force on Modernizing Income Security for Working-Age Adults (2006) 'Time for a fair deal.' Technical Report, St. Christopher House and Toronto City Summit Alliance, Toronto

Todd, Petra E., and Kenneth I. Wolpin (2006) 'Assessing the impact of a school subsidy program in mexico: Using a social experiment to validate a dynamic 
behavioral model of child schooling and fertility.' American Economic Review 96(5), 1384-1417

- (2008) 'Ex ante evaluation of social programs.' Annals of Economics and Statistics (91/92), pp. 263-291 
Table 2: Parameter Estimates of the Labor Supply Models

\begin{tabular}{|c|c|c|c|c|c|c|}
\hline Variable & Est & StdErr & Est & StdErr & Est & StdErr \\
\hline & \multicolumn{2}{|c|}{ Single Men } & \multicolumn{2}{|c|}{ Single Women } & \multicolumn{2}{|c|}{ Single Mothers } \\
\hline $\ln$ (Leisure) & 102.25 & 24.02 & 203.47 & 41.27 & 228.51 & 97.18 \\
\hline $\ln (\text { Leisure })^{2}$ & 1.32 & 0.8 & -2.47 & 1.56 & -3.93 & 1.40 \\
\hline $\ln ($ Leisure $) \times \ln ($ Age $)$ & -59.29 & 12.92 & -100.66 & 20.07 & -112.39 & 51.12 \\
\hline $\ln ($ Leisure $) \times \ln (\text { Age })^{2}$ & 8.09 & 1.8 & 14.04 & 2.75 & 16.06 & 6.98 \\
\hline $\ln ($ Leisure $) \times \mathrm{NB} 018$ & & & & & 0.44 & 0.41 \\
\hline $\ln ($ Leisure $) \times($ Preschool $>0)$ & & & & & 0.47 & 0.91 \\
\hline $\ln ($ Net income $)$ & 4.22 & 0.39 & 4.27 & 1.03 & -1.27 & 0.93 \\
\hline $\ln (\text { Net income })^{2}$ & 0.018 & 0.02 & 0.058 & 0.03 & 0.89 & 0.28 \\
\hline 40h/week $(\theta)$ & 2.02 & 0.13 & 1.9 & 0.18 & 1.34 & 0.26 \\
\hline \multicolumn{7}{|l|}{ Fixed Income (FI) } \\
\hline Constant $\left(\gamma_{0}\right)$ & -36.85 & 6.51 & -32.84 & 11.4 & & \\
\hline $\log ($ Age $)\left(\gamma_{1}\right)$ & 12.20 & 1.99 & 11.4 & 3.67 & & \\
\hline \multicolumn{7}{|l|}{ Fixed Costs (FC) } \\
\hline Constant $\left(\delta_{0}\right)$ & & & & & 5.57 & 0.30 \\
\hline Preschool $>0\left(\delta_{1}\right)$ & & & & & 6.78 & 2.84 \\
\hline
\end{tabular}


Table 3: Transition Matrices of Weekly Hours of Work, CCLP and 16 to 30 hours Cut-Off (\%)

\begin{tabular}{|c|c|c|c|c|c|c|c|c|c|}
\hline \multirow[b]{3}{*}{ Observed } & \multicolumn{8}{|c|}{ Single Men } & \multirow{3}{*}{ Total } \\
\hline & \multicolumn{8}{|c|}{ CCLP (Simulated) } & \\
\hline & {$[0,4[$} & {$[4,12[$} & {$[12,20[$} & {$[20,28[$} & {$[28,36[$} & {$[36,44[$} & {$[44,52[$} & {$[52,60[$} & \\
\hline$[0,4[$ & 11.60 & 0.02 & 0.0 & 0.0 & 0.0 & 0.0 & 0.0 & 0.0 & 11.63 \\
\hline$[4,12[$ & 0.04 & 2.06 & 0.0 & 0.0 & 0.0 & 0.0 & 0.0 & 0.0 & 2.11 \\
\hline$[12,20[$ & 0.31 & 0.11 & 3.56 & 0.0 & 0.0 & 0.0 & 0.0 & 0.0 & 3.98 \\
\hline$[20,28[$ & 0.96 & 0.19 & 0.06 & 4.87 & 0.0 & 0.0 & 0.0 & 0.0 & 6.08 \\
\hline$[28,36[$ & 1.28 & 0.33 & 0.07 & 0.0 & 9.36 & 0.0 & 0.0 & 0.0 & 11.04 \\
\hline$[36,44[$ & 9.98 & 1.85 & 0.53 & 0.03 & 0.0 & 43.85 & 0.0 & 0.0 & 56.24 \\
\hline$[44,52[$ & 0.6 & 0.09 & 0.02 & 0.0 & 0.0 & 0.0 & 2.94 & 0.0 & 3.65 \\
\hline$[52,60[$ & 0.62 & 0.09 & 0.02 & 0.0 & 0.0 & 0.0 & 0.0 & 4.55 & 5.28 \\
\hline Total & 25.34 & 4.74 & 4.26 & 4.9 & 9.36 & 43.85 & 2.94 & 4.55 & 100.0 \\
\hline \multirow[t]{2}{*}{ Change } & 13.77 & 2.63 & $0.29^{\dagger}$ & -1.18 & -1.68 & -12.39 & $-0.71^{\dagger}$ & $-0.73^{\dagger}$ & \\
\hline & \multicolumn{8}{|c|}{$80 \%-100 \%$ Cut-Off from 16 to 30 hours (Simulated) } & Total \\
\hline Total & 25.79 & 3.84 & 4.12 & 4.96 & 9.45 & 44.31 & 2.96 & 4.57 & 100.0 \\
\hline Change & 14.16 & 1.74 & 0.14 & -1.12 & -1.59 & -11.93 & -0.68 & -0.71 & \\
\hline
\end{tabular}

\begin{tabular}{|c|c|c|c|c|c|c|c|c|}
\hline \multirow[b]{3}{*}{ Observed } & \multicolumn{7}{|c|}{ Single Women } & \multirow{3}{*}{ Total } \\
\hline & \multicolumn{7}{|c|}{ CCLP (Simulated) } & \\
\hline & {$[0,4[$} & {$[4,12[$} & {$[12,20[$} & {$[20,28[$} & {$[28,36]$} & {$[36,44[$} & {$[44,52[$} & \\
\hline$[0,4[$ & 25.46 & 0.05 & 0.02 & 0.0 & 0.0 & 0.0 & 0.0 & 25.53 \\
\hline$[4,12[$ & 0.03 & 1.57 & 0.0 & 0.0 & 0.0 & 0.0 & 0.0 & 1.6 \\
\hline$[12,20[$ & 0.66 & 0.06 & 3.96 & 0.0 & 0.0 & 0.0 & 0.0 & 4.68 \\
\hline$[20,28[$ & 0.71 & 0.15 & 0.11 & 5.71 & 0.0 & 0.0 & 0.0 & 6.67 \\
\hline$[28,36[$ & 2.06 & 0.39 & 0.21 & 0.02 & 9.81 & 0.0 & 0.0 & 12.49 \\
\hline$[36,44[$ & 8.85 & 1.26 & 0.57 & 0.01 & 0.0 & 35.78 & 0.0 & 46.48 \\
\hline$[44,52[$ & 0.4 & 0.05 & 0.07 & 0.01 & 0.0 & 0.0 & 2.0 & 2.54 \\
\hline Total & 38.18 & 3.53 & 4.94 & 5.75 & 9.81 & 35.78 & 2.0 & 100.0 \\
\hline \multirow[t]{2}{*}{ Change } & 12.64 & 1.93 & $0.26^{\dagger}$ & -0.92 & -2.68 & -10.69 & -0.54 & \multirow{4}{*}{$\begin{array}{c}\text { Total } \\
100.0\end{array}$} \\
\hline & & $80 \%-1$ & $0 \% \mathrm{Cu}$ & Off from & 16 to 3 & hours ( & imulated) & \\
\hline Total & 38.51 & 2.97 & 4.7 & 5.79 & 9.95 & 36.08 & 2.01 & \\
\hline Change & 12.97 & 1.37 & 0.02 & -0.88 & -2.54 & -10.4 & -0.53 & \\
\hline
\end{tabular}

$\dagger$ The change is not statistically different from 0 at a $10 \%$ level.

Table 4: Simulated Impact of the CCLP Recommendation on Hours of Work, by Net Earnings Percentiles

\begin{tabular}{|c|c|c|c|c|c|}
\hline & Total & $0-10$ & $0-25$ & $75-100$ & $90-100$ \\
\hline \multicolumn{6}{|l|}{$\%$ Change, Intensive Margin } \\
\hline Single males & $-2.88 \% * * *$ & $-11.41 \% * * *$ & $-8.18 \% * * *$ & $-0.36 \% * * *$ & $-0.23 \% * * *$ \\
\hline Single females & $-2.88 \% * * *$ & $-13.06 \% * * *$ & $-9.96 \% * * *$ & $-0.71 \% * * *$ & $-0.54 \% * * *$ \\
\hline Single mothers & $-2.04 \% * * *$ & $-0.34 \% * *$ & $-1.22 \% * *$ & $-2.50 \% * * *$ & $-0.45 \% * * *$ \\
\hline \multicolumn{6}{|l|}{$\%$ Change, Extens } \\
\hline Single males & $-16.11 \% * *$ & $-30.22 \% * * *$ & $-26.82 \% * * *$ & $-7.12 \% * * *$ & $-6.41 \% * * *$ \\
\hline Single females & $-17.74 \% * *$ & $-29.21 \% * * *$ & $-30.10 \% * * *$ & $-10.06 \% * * *$ & $-6.00 \% * * *$ \\
\hline Single mothers & $-4.28 \% * * *$ & $6.74 \%$ & $-6.03 \% * * *$ & $-3.49 \% * *$ & $-1.61 \% * * *$ \\
\hline \multicolumn{6}{|l|}{$\%$ Change, Total } \\
\hline Single males & $-19.00 \% * * *$ & $-41.64 \% * *$ & $-35.00 \% * *$ & $-7.48 \% * *$ & $-6.64 \% * *$ \\
\hline Single females & $-20.62 \% * * *$ & $-42.26 \% * *$ & $-40.06 \% * *$ & $-10.78 \% * *$ & $-6.54 \% * *$ \\
\hline Single mothers & $-6.32 \% * * *$ & $-7.08 \% * * *$ & $-7.25 \% * * *$ & $-5.98 \% * * *$ & $-2.07 \% * * *$ \\
\hline
\end{tabular}

** Statistically significant at $5 \%$. ${ }^{* * *}$ Statistically significant at $1 \%$. 
Table 5: Transition Matrices of Weekly Hours of Work, 100\% MBM and 3\$/hour Subsidy (\%)

\begin{tabular}{|c|c|c|c|c|c|c|c|c|c|}
\hline \multirow[b]{3}{*}{ Observed } & \multicolumn{8}{|c|}{ Single Men } & \multirow{3}{*}{ Total } \\
\hline & \multicolumn{8}{|c|}{ 100\% MBM (Simulated) } & \\
\hline & {$[0,4[$} & {$[4,12]$} & {$[12,20 \mid$} & {$[20,28]$} & {$[28,36]$} & {$[36,44]$} & {$[44,52]$} & {$[52,60 \mid$} & \\
\hline$[0,4[$ & 11.63 & 0.0 & 0.0 & 0.0 & 0.0 & 0.0 & 0.0 & 0.0 & 11.63 \\
\hline$[4,12[$ & 0.13 & 1.97 & 0.0 & 0.0 & 0.0 & 0.0 & 0.0 & 0.0 & 2.11 \\
\hline$[12,20[$ & 0.68 & 0.1 & 3.19 & 0.0 & 0.0 & 0.0 & 0.0 & 0.0 & 3.98 \\
\hline$[20,28[$ & 1.46 & 0.18 & 0.05 & 4.39 & 0.0 & 0.0 & 0.0 & 0.0 & 6.08 \\
\hline$[28,36[$ & 2.18 & 0.29 & 0.05 & 0.0 & 8.52 & 0.0 & 0.0 & 0.0 & 11.04 \\
\hline$[36,44[$ & 15.69 & 1.65 & 0.36 & 0.02 & 0.0 & 38.52 & 0.0 & 0.0 & 56.24 \\
\hline$[44,52[$ & 0.93 & 0.08 & 0.02 & 0.0 & 0.0 & 0.0 & 2.62 & 0.0 & 3.65 \\
\hline$[52,60[$ & 0.96 & 0.08 & 0.02 & 0.0 & 0.0 & 0.0 & 0.0 & 4.22 & 5.28 \\
\hline Total & 33.66 & 4.37 & 3.68 & 4.42 & 8.52 & 38.52 & 2.62 & 4.22 & \multirow[t]{2}{*}{100.0} \\
\hline \multirow[t]{2}{*}{ Change } & 22.03 & 2.26 & -0.30 & -1.66 & -2.52 & -17.72 & -1.03 & -1.06 & \\
\hline & \multicolumn{8}{|c|}{ With $3 \$$ /hour Subsidy (Simulated) } & \multirow{3}{*}{$\begin{array}{c}\text { Total } \\
11.63\end{array}$} \\
\hline \multirow{2}{*}{$\begin{array}{l}{[0,4[} \\
\text { Change }\end{array}$} & 8.37 & 0.0 & 0.0 & 0.0 & 0.34 & 2.41 & 0.3 & 0.22 & \\
\hline & -3.26 & 0.0 & 0.0 & 0.0 & 0.34 & 2.41 & 0.3 & 0.22 & \\
\hline
\end{tabular}

\begin{tabular}{|c|c|c|c|c|c|c|c|c|}
\hline \multirow[b]{3}{*}{ Observed } & \multicolumn{7}{|c|}{ Single Women } & \multirow{3}{*}{ Total } \\
\hline & \multicolumn{7}{|c|}{ 100\% MBM (Simulated) } & \\
\hline & $\mid 0,4[$ & {$[4,12[$} & {$[12,20 \mid$} & {$[20,28 \mid$} & {$[28,36 \mid$} & {$[36,44 \mid$} & {$[44,52[$} & \\
\hline$[0,4[$ & 25.49 & 0.04 & 0.0 & 0.0 & 0.0 & 0.0 & 0.0 & 25.53 \\
\hline$[4,12[$ & 0.07 & 1.53 & 0.0 & 0.0 & 0.0 & 0.0 & 0.0 & 1.6 \\
\hline$[12,20[$ & 1.16 & 0.06 & 3.46 & 0.0 & 0.0 & 0.0 & 0.0 & 4.68 \\
\hline$[20,28[$ & 1.23 & 0.15 & 0.09 & 5.2 & 0.0 & 0.0 & 0.0 & 6.67 \\
\hline$[28,36[$ & 3.27 & 0.4 & 0.16 & 0.01 & 8.66 & 0.0 & 0.0 & 12.49 \\
\hline$[36,44[$ & 13.07 & 1.17 & 0.41 & 0.01 & 0.0 & 31.82 & 0.0 & 46.48 \\
\hline$[44,52[$ & 0.65 & 0.06 & 0.06 & 0.01 & 0.0 & 0.0 & 1.76 & 2.54 \\
\hline Total & 44.95 & 3.41 & 4.18 & 5.23 & 8.66 & 31.82 & 1.76 & \multirow[t]{5}{*}{100.0} \\
\hline \multirow[t]{2}{*}{ Change } & 19.41 & 1.80 & -0.5 & -1.44 & -3.83 & -14.66 & -0.78 & \\
\hline & \multicolumn{7}{|c|}{ With $3 \$$ /hour Subsidy (Simulated) } & \\
\hline \multirow{2}{*}{$\begin{array}{l}{[0,4[} \\
\text { Change }\end{array}$} & 21.5 & 0.0 & 0.0 & 0.0 & 0.71 & 3.12 & 0.21 & \\
\hline & -4.04 & 0.0 & 0.0 & 0.0 & 0.71 & 3.12 & 0.21 & \\
\hline
\end{tabular}

$\dagger$ The change is not statistically different from 0 at a $10 \%$ level. 


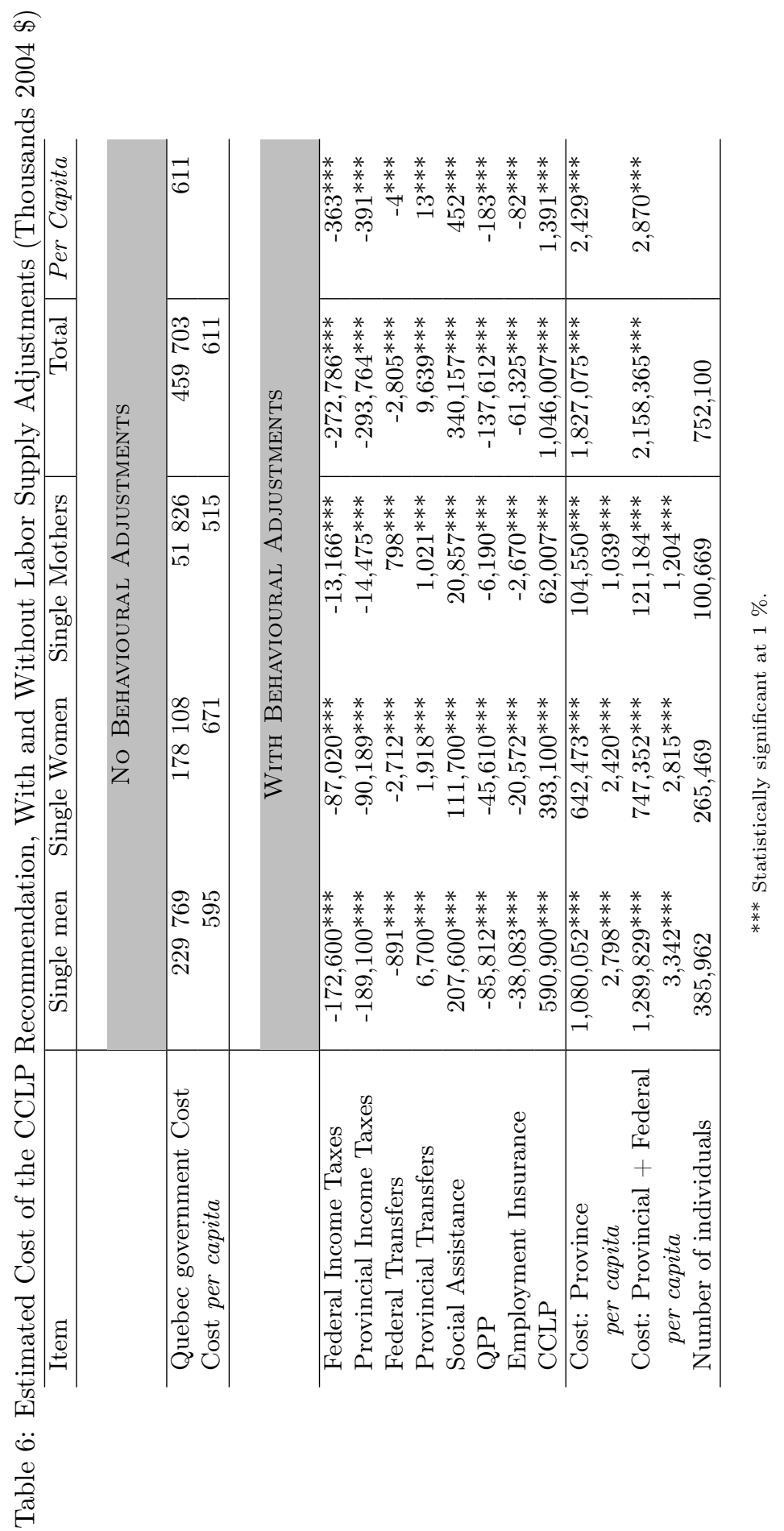


Table 7: Cost of Alternative Policy Simulations (Thousands \$)

\begin{tabular}{|c|c|c|c|c|}
\hline & $\begin{array}{l}\text { Single } \\
\text { Men }\end{array}$ & $\begin{array}{c}\text { Single } \\
\text { Women }\end{array}$ & $\begin{array}{c}\text { Single } \\
\text { Mothers }\end{array}$ & $\begin{array}{l}\text { Total } \\
\text { Total }\end{array}$ \\
\hline \multicolumn{5}{|c|}{ CCLP recommendation } \\
\hline Subsidy & 590,900 & 393,100 & 62,007 & $1,046,007$ \\
\hline Provincial Cost & $1,080,052$ & 642,473 & 104,550 & $1,827,074$ \\
\hline Total Cost & $1,289,829$ & 747,352 & 121,184 & $2,158,366$ \\
\hline Income increase (\%) & 11.9 & 14.0 & 5.3 & 11.8 \\
\hline Income decrease (\%) & 17.0 & 15.4 & 5.6 & 14.9 \\
\hline No change $(\%)$ & 71.1 & 70.6 & 89.1 & 73.3 \\
\hline \multicolumn{5}{|c|}{ CCLP with threshold at 30 Hours } \\
\hline Subsidy & 566,400 & 381,300 & 56,504 & $1,004,204$ \\
\hline Provincial Cost & $1,046,560$ & 626,863 & 97,050 & $1,770,473$ \\
\hline Total Cost & $1,249,056$ & 728,334 & 112,384 & $2,089,774$ \\
\hline Income increase (\%) & 11.9 & 13.9 & 5.3 & 11.8 \\
\hline Income decrease (\%) & 16.4 & 15.0 & 5.4 & 14.4 \\
\hline No change $(\%)$ & 71.7 & 71.1 & 89.4 & 73.9 \\
\hline \multicolumn{5}{|l|}{$100 \%$ of the MBM } \\
\hline Subsidy & $1,112,000$ & 708,500 & 132,100 & $1,952,600$ \\
\hline Provincial Cost & $1,881,864$ & $1,100,327$ & 222,618 & $3,204,810$ \\
\hline Total Cost & $2,198,815$ & $1,257,780$ & 253,925 & $3,710,520$ \\
\hline Income increase (\%) & 12.2 & 15.5 & 13.7 & 13.5 \\
\hline Income decrease (\%) & 24.1 & 20.8 & 8.2 & 20.8 \\
\hline No change $(\%)$ & 63.7 & 63.9 & 78.1 & 65.7 \\
\hline \multicolumn{5}{|c|}{$3 \$$ Wage subsidy for Non-Workers } \\
\hline Subsidy & 169,000 & 136,500 & 56,380 & 361,880 \\
\hline Provincial Cost & 99,911 & 72,473 & 28,928 & 201,312 \\
\hline Total Cost & 54,848 & 31,636 & 18,647 & 105,132 \\
\hline Income increase (\%) & 3.3 & 4.0 & 4.0 & 3.6 \\
\hline Income decrease (\%) & 0 & 0 & 0 & 0 \\
\hline No change $(\%)$ & 96.7 & 96.0 & 96.0 & 96.4 \\
\hline
\end{tabular}




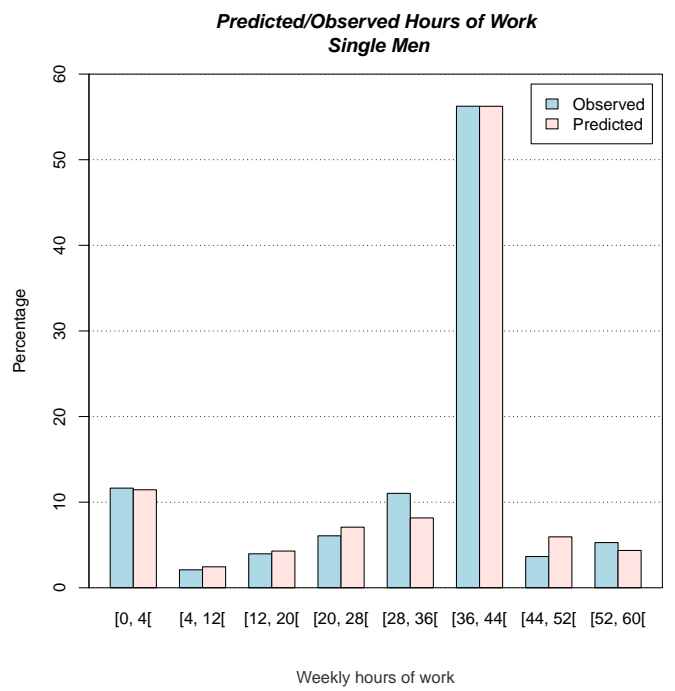

(a) Single Men

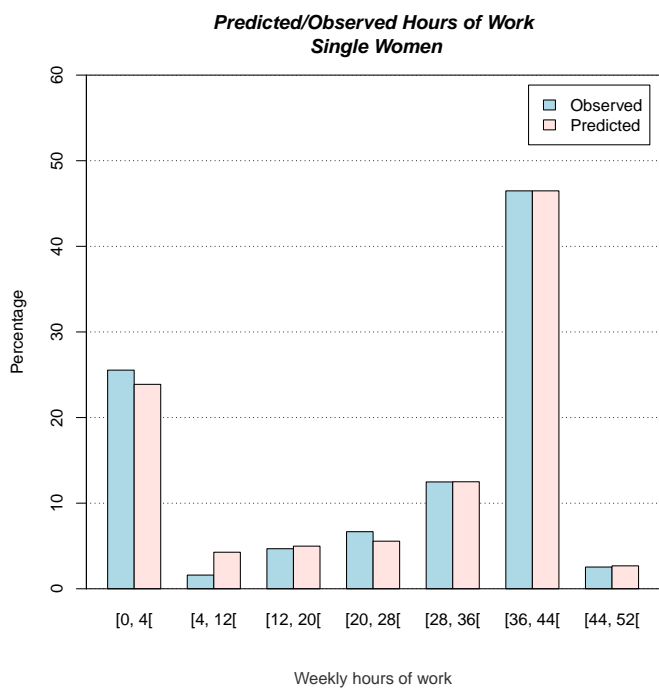

(b) Single Women

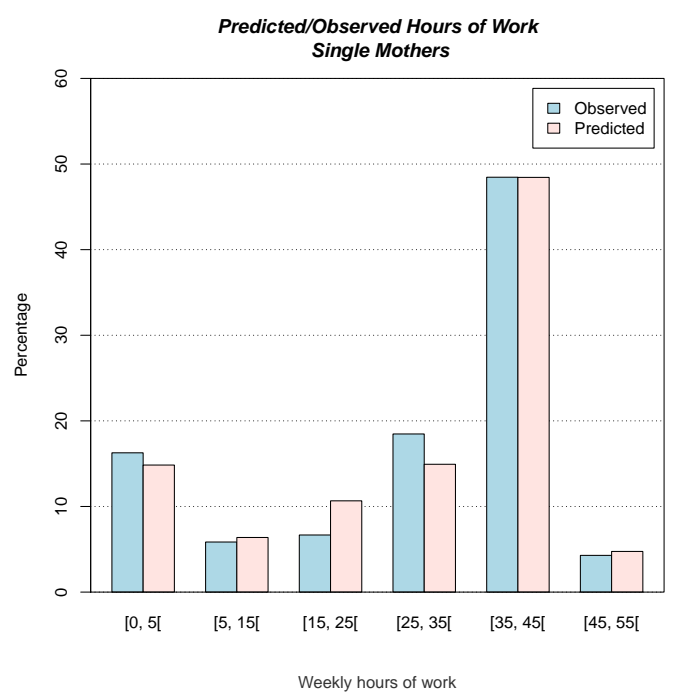

(c) Single Mothers

Figure 4: Model Fit for Different Samples 


\section{A Econometric Model}

In order to conduct coherent policy simulations, the labor supply model must investigate individual behaviour in a theoretically consistent manner. ${ }^{17}$. We follow Soest and Das (2001) and assume that the choice set facing an individual is given by $\left\{h^{1}, h^{2}, \ldots, h^{p}\right\}$, where $p$ is the number of possible choices of hours of work. Individuals are assumed to maximize the following well-behaved translog utility function:

$$
u^{i}\left(l^{i}, y^{i}\right)=\beta_{1} \log \left(l^{i}\right)+\beta_{2} \log \left(l^{i}\right)^{2}+\beta_{3} \log \left(y^{i}\right)+\beta_{4} \log \left(y^{i}\right)^{2} .
$$

This utility function is locally flexible to the second order and does not impose the quasi-concavity of preferences. ${ }^{18}$ Preference heterogeneity is introduced in the leisure parameter $\beta_{1}$ :

$$
\beta_{1}=\alpha_{0}+\alpha_{1} \log (\text { Age })+\alpha_{2} \log (\text { Age })^{2}+\alpha_{3} N B 018+\alpha_{4}(\text { Preschool }>0)+v
$$

where NB018 is the number of children below 18, and (Preschool $>0$ ) is a dummy variable equal to one when a preschooler is present in the household. Preferences for leisure also vary with unobserved characteristics, $v$, a random component assumed to be independently and identically distributed as a normal random variate with mean zero and variance $\sigma^{2}$.

To allow for optimization errors, we also assume that the utility function itself has a random term $\xi^{i}$ :

$$
U^{i}\left(l^{i}, y^{i}\right)=u^{i}\left(l^{i}, y^{i}\right)+\xi^{i}
$$

where $\xi^{i}$ is assumed to be independently and identically distributed as a Type-I extreme value random variate (namely, the Gumble distribution).

According to equation (A.3), an individual will choose $h^{i}$ if $u^{i}$ is greater than the utility associated with the other alternatives. Given the stochastic specification of the model, the probability this will happen, conditional on a given value of $v$, is given by:

$$
\operatorname{Pr}\left[U^{i} \geq U^{j}, \forall j\right]=\frac{\exp \left(u^{i}\left(l^{i}, y^{i}\right) \mid v\right)}{\sum_{j=1}^{p} \exp \left(u^{j}\left(l^{j}, y^{j}\right) \mid v\right)}
$$

The literature on discrete labor supply models has generally found that such models tend to under-predict the number of individuals with $h=0$. Fixed costs must be subtracted from income if $h>0$. The problem with this is that income 
minus fixed costs may be negative, a possibility that cannot be dealt with due to the form of the translog utility function. Gong and van Soest (2002) have introduced the notion of fixed income for not working. Instead of subtracting a fixed cost to work, a fixed income can be added to the income at zero hours of work, making inactivity a relatively more attractive alternative. Both approaches have the potential to capture the bunching at zero hours of work. For practical reasons, the model for single mothers is based upon the "fixed costs" approach, while the models for single males and females are based upon the "fixed income" approach. $^{19}$

Fixed incomes and fixed costs are incorporated into the model by replacing $u\left(y^{i}, l^{i}\right)$ by $u\left(y^{0}+F I, l^{0}\right)$ and $u\left(y^{i}-F C, l^{i}\right), \forall i>0$, respectively. The precise specification is

$$
\begin{aligned}
F I & =\gamma_{0}+\gamma_{1} \ln (A) \\
F C & =\delta_{0}+\delta_{1}(\text { Preschool }>0)
\end{aligned}
$$

Equation A.5 assumes that the fixed income is related to age and equation A.6 states that the fixed costs of working are associated with the presence of preschoolers. The two specifications could be made to depend on a richer set of covariates. To save on the degrees of freedom, the most parsimonious specification that nevertheless fitted the data well was selected.

We make one last modification to the standard model to account for the bunching of weekly hours of work around 40. We thus write:

$$
U^{i}\left(l^{i}, y^{i}\right)=u^{i}\left(l^{i}, y^{i}\right)+\theta(h=40)
$$

where $(h=40)$ is a dummy indicator equal to one if the individual works exactly 40 hours per week. The parameter $\theta$ proxies a fixed effect that increases the utility associated with working forty hours per week.

Finally, note that equation A.4 is written conditionally on a given realization of the random component $v$. The unconditional probability is obtained by integrating it out:

$$
\operatorname{Pr}\left[U^{i} \geq U^{j}, \forall j\right]=\int \frac{\exp \left(u^{i}\left(l^{i}, y^{i}\right) \mid v\right)}{\sum_{j=1}^{p} \exp \left(u^{j}\left(l^{j}, y^{j}\right) \mid v\right)} \phi\left(v ; 0, \sigma^{2}\right) d v,
$$

where $\phi$ is the density of $v$. Because $v$ is assumed to follow a normal distribution, 
equation A.8 does not have a closed-form solution. We thus simulate the integration by drawing $R=100$ draws of $v_{q}, q=1, \ldots, R$, from the normal distribution for each observation and compute the expected probability (3.3) as:

$$
\widehat{\operatorname{Pr}}\left[u^{i} \geq u^{j} \forall j\right]=\frac{1}{R} \sum_{q=1}^{R} \frac{\exp \left(u^{i}\left(l^{i}, y^{i}\right) \mid v_{q}\right)}{\sum_{j=1}^{p} \exp \left(u^{j}\left(l^{j}, y^{j}\right) \mid v_{q}\right)}
$$

The maximization of the simulated likelihood function yields consistent and efficient parameter estimates if $\sqrt{N} / R \rightarrow 0$ when $R \rightarrow+\infty$ and $N \rightarrow+\infty$ ( $N$ being the number of observations; see Gouriéroux and Monfort 1991; 1996). ${ }^{20}$

The parameter estimates on fixed income reported in Table 2 tell an interesting story. The parameter associated with $\log (A g e)$ is positive for both single males and females and is highly statistically significant. Older singles thus behave as though they have stronger preferences for leisure. Likewise, the parameter associated with $(h=40)$ is also positive and highly statistically significant. In our framework, this is equivalent to depicting a strong preference for working the standard workweek.

The parameters of the fixed costs term are also intuitively consistent. The parameter estimates show that the fixed costs to work increase when preschoolers are present in the household. They thus make working a less attractive alternative. Single mothers, like single males and females, also behave as though they have a strong preference for the standard workweek. 